\title{
CIÊNCIA, TECNOLOGIA E SOCIEDADE; TRABALHO E EDUCAÇÃO: POSSIBILIDADES DE INTEGRAÇÃO NO CURRÍCULO DA EDUCAÇÃO PROFISSIONAL TECNOLÓGICA
}

\author{
Abelardo Bento Araújo* \\ Maria Aparecida da Silva**
}

RESUMO: Supondo haver lacunas na produção teórica sobre Currículo, especialmente integrando os campos Ciência, Tecnologia e Sociedade (CTS) e Trabalho e Educação (T\&E), este artigo questiona a possibilidade de integrar os pressupostos desses campos no currículo da Educação Profissional e Tecnológica (EPT). Ciente da impossibilidade de responder cabalmente à indagação, o texto pretende ser ponto de partida para discussões futuras. Primeiramente, analisam-se as obras $A$ estrutura das revoluções cientificas, de Thomas Kuhn, e Primavera silenciosa, de Rachel Carson, publicadas no ano de 1962 - dialogando-se com autores que discutem CTS em educação. Em um segundo momento, analisam-se produções contemporâneas sobre os vínculos entre T\&E na sociedade capitalista, evidenciando-se possibilidades de integração entre os dois campos, relacionando-os ao currículo da EPT.

Palavras-chave: CTS, T\&E, currículo.

SCIENCE, TECHNOLOGY AND SOCIETY; WORK AND EDUCATION: OPPORTUNITIES IN CURRICULUM INTEGRATION OF PROFESSIONAL AND TECHNOLOGIC EDUCATION

ABSTRACT: Assuming there are gaps in the theoretical production of the field of curriculum, especially integrating the fields Science, Technology and Society (CTS) and Labor and Education (T\&E), this article questions the possibility of integrating the assumptions of these fields in the curriculum of Vocational and Technological Education (VTE). Aware of the impossibility to fully respond to the inquiry, the text aims to be a starting point for future discussions. First, we analyze the works The Structure of Scientific Revolutions, by Thomas Kuhn, and Silent Spring, by Rachel Carson, published in 1962 - in dialogue with authors discussing CTS in education. Secondly, we analyze contemporary productions about the links between T\&E in capitalist society, showing the possibilities of integration between the two fields, linking them to the curriculum of the VTE.

Keywords: CTS, T\&E, curriculum. 


\section{INTRODUÇÃO}

A concepção de um currículo que tenha como eixo ciência, tecnologia e sociedade com vistas à formação do trabalhador pressupõe compreender concepções subjacentes, tais como concepção de sociedade, de homem, de trabalho, de ciência, de técnica, de educação e, como parte desta, de educação científica e tecnológica. Pressupõe ainda compreender as relações entre essas concepções.

A densidade desse tema exige respostas parcelares para se chegar ao seu cerne. Assim, este texto tem como norteadora a pergunta: é possível integrar numa proposta curricular para a Educação Profissional e Tecnológica (EPT) os pressupostos do campo ${ }^{1}$ Ciência, Tecnologia e Sociedade (CTS) com os do campo Trabalho e Educação (T\&E)? A pergunta leva a outras. Existem antagonismos entre esses eixos? Quais os pontos de convergência entre esses campos? Que pressupostos teóricos de um e de outro campo podem dar suporte à elaboração de proposta de currículo para a EPT? Os pressupostos teóricos de ambos os campos podem se complementar tendo em vista a fundamentação de proposta de currículo para a EPT? Mais que identificar possibilidades de aproximações entre CTS e T\&E, pretende-se com este artigo levantar discussões que possam consolidar conexões entre esses campos, contribuindo-se para a construção de propostas de currículo de EPT.

No campo T\&E, autores como Frigotto (1998), Ciavatta (2005; 2006), entre outros, vêm discutindo a EPT e a definição de propostas de currículo para essa modalidade de educação no Brasil. As discussões buscam compreender a educação profissional no interior da sociedade capitalista, mostrando, entre outras questões, as relações entre a dualidade estrutural da sociedade brasileira assentada no modo capitalista de produção e a dualidade educacional, refletida nas propostas curriculares dessa modalidade de educação. Em contraposição à EPT com orientação dual, esses autores, com base em Marx e Gramsci, vêm se contrapondo às propostas que separam o pensar do fazer. Considera-se que uma proposta de educação que pretenda a amplitude subjacente a essa visão de educação não pode prescindir da discussão sobre o trabalho na sociedade atual, sobre o desenvolvimento científico-tecnológico e suas implicações para a educação.

O movimento CTS aponta a necessidade de se repensarem as relações entre homem, ciência, tecnologia e sociedade. As investigações educacionais nesse campo têm sido realizadas por autores espanhóis e portugueses e, no Brasil, vêm ganhando visibilidade por meio de autores como Auler, Bazzo (2001); Santos, Mortimer (2002); Pinheiro, Silveira, Bazzo (2007). Pressupõe-se, nesse sentido, que a dimensão política do campo T\&E possa se integrar às discussões no interior do campo CTS, ampliando seus pressupostos o oferecendo possibilidades à EPT. $\mathrm{O}$ artigo se divide em quatro partes, além da introdução. Na primeira, contextualizam-se o movimento CTS e os fundamentos que poderão subsidiar as discussões sobre currículo, a partir de duas obras pioneiras desse movimento: Kuhn (1998) e Carson (1969) ${ }^{2}$. As propostas de EPT, segundo o campo T\&E, serão objeto da 
segunda parte. A terceira parte se ocupa dos pressupostos curriculares de ambos os campos, evidenciando possibilidades de integração. Por fim, apresentam-se as considerações finais, procurando se responder à pergunta norteadora do artigo.

\section{MOVIMENTO CTS: OBRAS PIONEIRAS}

O acúmulo de experiências durante a Segunda Guerra Mundial pôs em pauta as questões que circundavam o avanço científico e tecnológico, discutindose as relações entre esse avanço e o bem-estar social. Por causa da atribuição de muitas catástrofes ao desenvolvimento da ciência, esta passou a ser vista com um olhar mais crítico. Porém, mesmo com o fim da guerra, em 1945, os questionamentos não ecoaram significativamente na sociedade. Tratava-se de manifestações localizadas, não podendo ser concebidas ainda como um movimento, mas elas viriam, mais tarde a ficar conhecidas como movimento Ciência, Tecnologia e Sociedade (movimento CTS).

As obras de Thomas Samuel Kuhn e de Rachel Carson são apontadas como precursoras do movimento ou, pelo menos, como síntese do pensamento da sociedade em relação à ciência na década de 1960 (AULER; BAZZO, 2001). A fim de se revelarem os pressupostos do movimento CTS e as relações deste com a educação, tomam-se essas obras como objeto de discussão.

Thomas Samuel Kuhn - físico teórico - inicia seus estudos sobre história e filosofia da ciência a partir de um convite para atuar junto ao Center for Advanced Studies, no Behavioral Sciences. Lá, ele começa a pensar sobre as diferenças entre a busca de respostas aos problemas científicos por cientistas da natureza e por cientistas sociais. Os questionamentos de Kuhn deram origem, no ano de 1962, à obra $A$ estrutura das revoluçoes científicas. O questionamento principal feito por Kuhn (1998) nessa obra recai sobre a ideia de progresso da ciência. O autor evidencia a perspectiva contraditória do desenvolvimento científico, marcado por revoluções paradigmáticas. Assim, Kuhn deixa clara a ideia de paradigma científico, em oposição à ideia positivista de desenvolvimento cumulativo, em linha reta. Paradigmas são, de acordo com esse teórico, "realizações científicas universalmente reconhecidas que, durante algum tempo, fornecem problemas e soluções modelares para uma comunidade de praticantes de uma ciência” (KUHN, 1998, p. 13). As revoluções científicas se definem, assim, pela superação de um modelo (paradigma) por outro em determinada área, obrigando os cientistas e profissionais a reformularem os princípios em que tal área está baseada. Essa análise leva em conta também o papel de fatores externos na emergência das crises e da transformação do paradigma e da prática científica.

A principal contribuição de Kuhn (1998) para a emergência do movimento CTS está em sua perspectiva de história e historiografia do desenvolvimento científico. Na introdução de sua obra, o autor deixa claro o papel que tem a história no entendimento do que é a ciência. A partir dos registros históricos da 
atividade de pesquisa, Kuhn se propõe a esboçar um novo conceito de ciência, um conceito diferente do estereótipo a-histórico contido em livros e manuais da época a respeito da ciência e do que fossem seus métodos.

A concepção de desenvolvimento por acumulação também implicava um papel para a história da ciência. Assim, caberia ao historiador registrar os fatos e leis científicos cumulativamente, apontando, descrevendo e explicando os amontoados de erros e outros empecilhos à acumulação mais rápida do conhecimento. Ainda segundo Kuhn (1998), as investigações sobre o que fizeram cientistas do passado revelam aos historiadores, nesse momento, que as antigas descobertas não são menos científicas que as recentes. Isso mostra que o desenvolvimento da ciência ocorre de modo diferente do subjacente à ideia de desenvolvimento cumulativo e provoca uma revolução historiográfica nos anos 1960. Em vez de perguntar sobre a relação entre a ciência de Galileu e a ciência dos anos 1950, os pesquisadores e cientistas passam a perguntar sobre a relação entre as concepções de Galileu e aquelas partilhadas por seu grupo. Essa ideia dá o sentido de contexto ao desenvolvimento da ciência. A partir desses estudos históricos, Kuhn (1998, p. 22) pergunta "que aspectos da ciência revelar-se-ão como proeminentes no desenrolar desse esforço?”. A essa pergunta, o próprio autor responde que, em princípio, as diretrizes metodológicas de uma ciência são insuficientes para ditar as conclusões sobre as questões científicas.

Vale salientar que Kuhn (1998) estabelece uma relação direta entre a educação científica e a legitimidade dos problemas e soluções científicos. Com efeito, a educação científica é, segundo o autor, um dos fatores responsáveis pela determinação da relevância desses problemas e soluções, porque

[...] os cientistas nunca aprendem conceitos, leis e teorias de uma forma abstrata e isoladamente. Em lugar disso, esses instrumentos intelectuais são desde o início, encontrados numa unidade histórica e pedagogicamente anterior, onde são apresentados juntamente com suas aplicações a uma determinada gama concreta de fenômenos naturais; sem elas, não poderia nem mesmo candidatar-se à aceitação científica. Depois de aceitas, essas aplicações (ou mesmo outras) acompanharão a teoria nos manuais onde os futuros cientistas aprenderão o seu ofício. As aplicações não estão lá simplesmente como um adorno ou mesmo como documentação. Ao contrário, o processo de aprendizado de uma teoria depende do estudo das aplicações, incluindo-se aí a prática na resolução de problemas, seja com lápis e papel, seja com instrumentos num laboratório (KUHN, 1998, p. 71).

As afirmações de Kuhn referem-se à formação do profissional cientista, como indivíduo que passará a compor um grupo, a partilhar opiniões e um ofício. Kuhn (1998) contribui significativamente com os questionamentos daquela época em relação à ciência, por vincular o processo de formação científica a sua aplicabilidade - não em um sentido pragmático, mas contextual, que passa por uma legitimação, isto é, a formação científica está relacionada à formação de valores que legitimam problemas e soluções científicos.

A partir da verificação da necessidade da legitimação dos problemas e 
soluções científicos por Kuhn, compreende-se tanto o vínculo direto entre realidade social e ciência quanto a possibilidade de se discutirem as relações entre ciência, sociedade e educação. Assim, a ciência vincula-se à sociedade como ambiente no qual pretende incidir e o ensino dela não se faz de modo isolado. Não se trata de se atribuir à ciência um papel pragmático, muito menos imediatista. Trata-se de entender que a finalidade de todo o esforço científico é a sociedade, e, portanto, o desenvolvimento científico leva em consideração a relevância e a plausibilidade de seu projeto - que, imediatista ou não, tem sempre como finalidade a sociedade. A natureza da educação científica a vincula à realidade objetiva e não prescinde da discussão sobre as relações entre desenvolvimento científico-tecnológico e impactos sociais.

Ao tratar do tema "a natureza e a necessidade das revoluções científicas", Kuhn (1998, p. 125) esclarece que são "revoluções científicas aqueles episódios de desenvolvimento não-cumulativo, nos quais um paradigma mais antigo é total ou parcialmente substituído por um novo, incompatível com o anterior". Para explicar essa afirmação, o autor estabelece um paralelo entre as revoluções políticas e as revoluções científicas. Em ambos os casos, o que provoca a crise é o crescimento do sentimento de que paradigmas científicos ou instituições políticas já não respondem às questões colocadas pelo meio. As crises são o prelúdio das revoluções, tanto em um como em outro caso. "As revoluções [...] [são] mudanças de concepção de mundo" (KUHN, 1998, p. 145).

As mudanças de paradigmas levam à percepção de novos contornos nos mesmos objetos. "O que um homem vê depende tanto daquilo que ele olha como daquilo que sua experiência visual-conceitual prévia o ensinou a ver. Na ausência de tal treino, somente pode haver [...] confusão atordoante e intensa"' (KUHN, 1998, p. 149). Nessa passagem, o autor se refere à teoria da Gestalt, mostrando que a forma de apreensão dos problemas científicos depende da maneira como se apreendem os objetos de pesquisa. Esse entendimento conduz, mais uma vez, a discussão para o campo da educação científica. A formação desempenha, assim, papel de fundamental importância na abordagem da relação entre problemas científicos e sociedade. O problema da educação científica também está relacionado aos manuais científicos, que subsidiam a formação dos cientistas e perpetuam a ciência normal, isto é, aquela ciência que se desenvolve sem conflitos que levem à necessidade de novos paradigmas. Kuhn (1998) critica a ciência presente nesses manuais porque, neles, a evolução da ciência desconsidera perdas, evidenciando apenas o sucesso científico.

Na segunda edição, publicada em 1969, sete anos depois da primeira, Kuhn reconhece que em sua obra deu pouca atenção à importância dos valores na determinação dos paradigmas e, então, refere-se a eles em um posfácio feito a pedido de um amigo, para a publicação da edição japonesa: "[...] penso que uma fraqueza do meu texto original está na pouca atenção prestada a valores como a coerência interna e externa ao considerar fontes de crises e fatores que determi- 
nam a escolha de uma teoria" (KUHN, 1998, p. 229-230).

Primeiro, o autor se refere a valores que devem permitir a formulação de quebra-cabeças (problemas da ciência normal - que podem ser resolvidos sem resultar em um novo paradigma), a coerência interna e a compatibilidade com outras teorias vigentes. Acrescenta, porém, que "existem ainda outras espécies de valores - por exemplo, a ciência deve ou não ter uma utilidade social?” (KUHN, 1998, p. 230). Essa talvez seja a questão que mais tenha afinidade com o movimento CTS.

A obra de Kuhn (1998) obviamente não se esgota nos limites dos objetivos deste texto. Os detalhes e sentidos dessa obra extrapolam o objetivo desta discussão.

Este texto não poderia deixar de tratar de outra obra também escrita nos intensos anos 1960 e que refletiu os questionamentos da época. Trata-se de Primavera silenciosa, publicada nos Estados Unidos pela bióloga marinha e poetiza Rachel Carson, no ano de 1962. Nessa época, a autora já havia publicado outras obras, incluindo um best-seller chamado $O$ mar que nos cerca, e enfrentava ferrenhas batalhas com a nascente indústria química, além de críticas infundadas da mídia manipulada pelo capital.

Em 2006, o jornal The Guardian ${ }^{3}$ a reconheceu como uma das pessoas que mais contribuíram com a defesa do meio ambiente. O jornal também publicou diversos artigos em que Carson aparece como pioneira do ambientalismo, entre eles o de Burnside (2002). Primavera silenciosa é, ao mesmo tempo, um relatório científico com dados precisos e a concretização de um movimento social. O caráter de movimento social é evidenciado pela referência e publicação, pela autora, de diversas cartas de habitantes dos Estados Unidos e do mundo, as quais ela extrai das sessões de cartas de diversos jornais. A obra reúne dados de jornais e revistas científicos de todo o mundo, apreendendo "ecos de todas as partes do Globo" (CARSON, 1969, p. 132).

O título da obra de Carson refere-se à chegada silenciosa da primavera nos Estados Unidos. Segundo a autora, em áreas cada vez mais extensas de seu país, a primavera chegava "sem ser anunciada pelo regresso dos pássaros; e as madrugadas se apresentam estranhamente silenciosas, nas regiões em que outrora se enchiam da beleza do canto das aves" (CARSON, 1969, p. 113).

As principais críticas de Carson (1969) se dirigem à introdução de substâncias não orgânicas na natureza. Os alvos principais de suas críticas são os inseticidas e herbicidas, entre eles o DDT (dicloro-difenil-tricloro-etano) e o BHC (hexacloreto de benzeno). O DDT, criado para higienização (matar piolhos e vetores de doenças venéreas, principalmente) no período da guerra, passa a ser utilizado em larga escala em lavouras, tendo sido descobertos, mais tarde, seus malefícios à saúde humana e à dos animais, especialmente no tocante à reprodução de pássaros. Essa substância (mais tarde proibida) diminui a concentração de cálcio nas cascas dos ovos, fazendo-os quebrar antes que os filhotes nasçam, com a pos- 
sibilidade de extermínio de espécies inteiras. O BHC tem como principal efeito maléfico conhecido a interrupção da nitrificação, processo pelo qual o nitrogênio disponível na atmosfera se torna aproveitável para as plantas.

Carson (1969) reúne dados de relatórios científicos de respeitados pesquisadores em áreas como a farmacologia, a química e a biologia. A autora mostra, com isso, que boa parte dos efeitos desses produtos já era conhecida à época.

Com seus questionamentos, a autora não propõe o abandono da produção de alimentos, mas afirma que havia maneiras de se controlarem pragas e, ao mesmo tempo, preservar fauna e flora. Ela também critica a política estadunidense de regulação dos inseticidas e herbicidas, propondo: "A primeira necessidade é [a] da eliminação das tolerâncias concedidas aos hidrocarbonetos clorados, aos pesticidas do grupo do fósforo orgânico e a outras substâncias químicas altamente tóxicas" (CARSON, 1969, p. 197).

Nesse sentido, a autora alerta para uma inversão de preocupação. Se, em um primeiro momento, a busca era por se combaterem os insetos, em um segundo, poderia ser por remédios para os males causados pelos inseticidas. Com isso, Carson reivindica outra forma de se ver a ciência. Em suas palavras: "Estamos acostumados a procurar o efeito grosseiro e imediato, e a ignorar tudo o mais. A menos que este efeito surja de pronto, e de forma tão óbvia que não possa ser ignorado, nós negamos a existência do risco" (CARSON, 1969, p. 197).

Carson também temia danos à herança genética, por esta ser o vínculo da espécie com seu passado e seu futuro. Diante do que vinha acontecendo com os insetos em meio à utilização de inseticidas, a autora afirma que "o próprio Darwin mal poderia encontrar melhor exemplo do processo pelo qual se opera a seleção natural [...]" (CARSON, 1969, p. 279). Segundo ela, Darwin se surpreenderia com a confirmação das teorias por ele elaboradas, mediante a observação da sobrevivência dos insetos mais aptos, de gerações cada vez mais resistentes, que implica numa guerra cíclica do homem contra a Natureza.

Diversas análises têm sido feitas sobre a obra de Carson. Algumas têm se referido apenas à discussão em torno dos pesticidas, mas isso seria limitar demais um pensamento tão revolucionário. Burnside (2002) compara o pensamento da bióloga, a quem ele chama de "improvável fundadora do movimento ecológico radical", ao de Heidegger, quando a mesma reclama uma nova maneira de pensar o mundo no século XX. Ela exigiu não apenas o fim do uso indiscriminado de pesticidas, mas uma nova ciência, uma nova filosofia para a ciência. Reclamou a necessidade de se repensar a relação homem-natureza mediada pela ciência e a tecnologia.

Diante da importância das contribuições do pensamento dessa autora, salienta-se que este artigo não tem a pretensão de esgotá-las, mas tão somente de extrair o legado dos pressupostos nela contidos para o movimento CTS e, consequentemente, para CTS em educação.

As obras de Carson (1969) e Kuhn (1998) não tratam especificamente 
de educação, embora não seja difícil estabelecer relações entre as concepções de ciência que apresentam e a educação científica. Essas obras expressam a inviabilidade do tipo de desenvolvimento científico e tecnológico que se vinha cultivando em face das evidências histórico-científicas. Aquelas relações entre homem, sociedade, ciência e natureza não eram mais compatíveis. Esses pressupostos fizeram-se presentes no movimento CTS, emergente na mesma década de publicação das obras. Expunha-se, assim, a necessidade de se repensarem essas relações. Esse movimento teve repercussões na educação e no currículo, especialmente por meio do ensino de ciências.

\section{TRABALHO \& EDUCAÇÃO E EPT}

A EPT vem sendo discutida no bojo das pesquisas e teorias do campo T\&E. Compreender os objetivos dessa modalidade de educação numa perspectiva crítica requer, assim, explicitar as conclusões a que se vem chegando nesse campo. Segundo Arroyo (1991), essas teorizações passaram por longos debates antes de chegarem aos contornos com que se apresentam no início do século XXI.

O primeiro viés das discussões nesse campo é chamado por Arroyo (1991) de pessimismo culturalista, que vê no trabalho a degradação do homem. A abordagem do trabalho nos currículos ocorria como defesa "contra os estragos culturais do trabalho fabril. Ainda que inspirada na crítica ao trabalho capitalista, essa postura termina somando-se à defesa das velhas formas de produção e de relações sociais", negando as propostas progressistas de trabalho como principio educativo (ARROYO, 1992, p. 165).

A segunda perspectiva que se ocupou da questão é chamada de determinismo tecnológico. Nesse entendimento, os avanços tecnológicos são invenções maléficas impostas ao homem e contra as quais a escola tem de prevenir o futuro trabalhador. O escolanovismo faz menção à superação do determinismo tecnológico com a proposta de ensino ativo, mas continuou a ver a escola em oposição à fábrica, como locais da alta e da baixa cultura, respectivamente. Interpretava-se o avanço tecnológico como ferramenta de dominação do trabalhador.

Como alternativa às interpretações da ciência e da técnica como ferramentas do controle do processo de trabalho e do capital, surgem as discussões progressistas. Estas pressupõem a compreensão sobre o trabalho e a educação no interior da sociedade capitalista como ponto de partida para o entendimento dos condicionamentos da EPT, assim como para o delineamento dos seus objetivos. Nessas discussões, a crítica à dualidade educacional continua presente, pois persiste na realidade, não podendo, portanto, a teoria omitir-se. A dualidade se desdobra na redução da concepção curricular, contrapondo-se à concepção de educação unitária, integrada, politécnica e, mais recentemente, de educação tecnológica. Esses conceitos relacionados à educação profissional visam a "responder, também, às necessidades do mundo do trabalho permeado pela presença da ciência 
Ciência, tecnologia e sociedade; trabalho e educação: possibilidades de integração no currículo da educação profissional tecnológica

e da tecnologia como forças produtivas, geradoras de valores, fontes de riqueza" (CIAVATTA, 2005, p. 03).

A defesa de teóricos como Frigotto (1998; 2007) e Ciavatta (2005; 2006) tem permitido uma contraproposta à utilização dessa modalidade de educação a serviço do capital. Esses autores têm se dedicado a mostrar as contradições e tentativas de redução da concepção de EPT. Referenciando-se em Marx e Gramsci, eles defendem as propostas progressistas, elegendo o trabalho como princípio educativo e recusando a concepção de educação profissional como simples preparo para o exercício de tarefas no mercado de trabalho. Essas são propostas que se pautam pela compreensão dos princípios e fundamentos científicos do processo de produção e por uma ampla concepção de educação profissional.

Em relação ao reducionismo das propostas de formação profissional no plano político, no Brasil, Frigotto (2007) busca entender a proposta de universalização da educação básica e sua relação com a EPT. Com base em apontamentos sobre a formação histórica, social, econômica do Brasil, o autor pergunta:

\footnotetext{
Que tipo de projeto de educação escolar básica e de formação profissional e tecnológica se coloca como necessário para uma sociedade que moderniza o arcaico e onde o atraso de determinados setores, a hipertrofia do trabalho informal e a precarização do trabalho formal, o analfabetismo etc. não são obstáculos ou impeditivos ao tipo de desenvolvimento que se ergueu pela desigualdade e se alimenta dela? (FRIGOTTO, 2007, p. 1135 - grifos do autor).
}

A partir dessa pergunta, esse autor mostra como foram abortados, sucessivamente, os projetos societários de reforma estrutural e investimento em educação, ciência e tecnologia, condições de constituição de uma nação soberana. Para o autor, a própria criação do Decreto n ${ }^{\circ}$. 2.208/97, que instituiu a Reforma da Educação profissional nos anos 90, no Brasil, representa a sequência desses retrocessos. O referido decreto foi, por excelência, o grande inviabilizador da educação politécnica nos Centros Federais de Educação Tecnológica, locais onde era possível a realização de uma educação capaz de oferecer os "fundamentos científicos gerais de todos os processos de produção e das diferentes dimensões da vida humana" (FRIGOT'TO, 2007, p. 1.139). O autor ainda alerta para o perigo da apropriação da expressão "educação tecnológica" na denominação da educação profissional como falseamento da concepção vigente.

Ciavatta (2006), ao refletir sobre a sucessiva transformação dos centros federais de educação tecnológica em instituições de ensino superior, explicita a necessidade de se pensar que tipo de sujeito se quer formar. A autora propõe que a reflexão comece sobre a ciência, a técnica, a tecnologia e suas relações com o trabalho e a educação, mencionando um artigo de Leonardo Boff (2004). Nesse texto, o autor mostra a importância da ciência e da tecnologia na convivência com o mundo atual, assim como o lado da relação com a natureza. Assim, Ciavatta escreve: 
Esse fato nos coloca diante de três exigências nos processos educacionais: primeiro, a científica, a proximidade com a ciência e a tecnologia, que nos permitem conhecer fatos como esse e manipular instrumentos que proporcionam conhecimentos e ações impensáveis para gerações passadas. Segundo, uma exigência ética, a interação do homem com a natureza está produzindo transformações de alcance imprevisíveis e parece que está se rompendo gradativamente o equilíbrio interativo que permite a sobrevivência humana. Por último, a educacional, a formação humana de crianças, adolescentes e jovens para o mundo de hoje exige domínio de conhecimentos globais das ciências, das tecnologias e a socialização para uma convivência com o planeta e a humanidade, de modo a preservar a vida (CIAVATTA, 2006, p. 913).

As reflexões dessa autora mencionam a necessidade de se refletir sobre o lugar da ciência e da tecnologia na formação na EPT, o que é afim às discussões do campo CTS. O papel da educação, numa perspectiva de totalidade, é formar atitudes em face da emergência do novo tipo de sociedade.

Localizam-se, assim, as conquistas da ciência e da tecnologia como não neutras em seus efeitos éticos e sociais, exigindo-se, portanto, um posicionamento da educação. Buscando referência em Thomas Kuhn, Grinspun (2003) supõe a necessidade de um novo paradigma em educação para se atender aos problemas e soluções de um novo tempo, um paradigma que se firme sobre os princípios da objetividade, transdisciplinaridade, subjetividade e sobre a categoria da totalidade. A autora ainda define a tecnologia como aplicação de teorias, métodos e processos científicos, com a principal finalidade de aumentar a capacidade humana de atividade. Grinspun (2003) difere sua perspectiva da cisão otimista, que pensa a tecnologia a partir do ponto de vista da liberação do homem para atividades criativas, e da postura pessimista, que postula a alienação humana do trabalho. O compromisso da educação, para a autora, é lidar com as dimensões educacional e social da tecnologia. Essa compreensão vai ao encontro da definição de educação tecnológica exposta por Oliveira (2000, p. 42), pautada pelo compromisso com o domínio "dos processos físicos e organizacionais ligados aos arranjos materiais e sociais, e do conhecimento aplicado e aplicável, pelo domínio dos princípios científicos e tecnológicos próprios a um determinado ramo de atividade humana". A compreensão do que seja educação tecnológica implica o entendimento tanto da tecnologia quanto da educação em âmbitos mais amplos, isto é, no bojo de relações sócio-históricas.

\section{CTS E T\&E: PRESSUPOSTOS CURRICULARES}

O movimento CTS não foi educacional, mas repercutiu na educação, incidindo, por decorrência, sobre o currículo. As discussões dos pressupostos desse movimento na educação têm sido realizadas por autores e pesquisadores da Península Ibérica, como Medina e Sanmartín (1990). Esses autores têm se dedicado a estudar as implicações do movimento CTS na educação e no currículo e a apontar os objetivos da abordagem CTS na educação. 
Nesse sentido, os objetivos curriculares devem se referir: (i) ao questionamento das formas herdadas de estudar e atuar sobre a natureza; (ii) à contextualização, pela escola, dos conhecimentos em relação às necessidades sociais; (iii) à integração entre conhecimento teórico e conhecimento prático; (iv) ao combate à segmentação do conhecimento; (v) à promoção da autenticidade da democracia do conhecimento científico e tecnológico. Visa-se, além da difusão do conhecimento, à integração dele na atividade produtiva das comunidades de forma crítica (MEDINA; SANMARTÍN, 1990, apud PINHEIRO; SILVEIRA; BAZZO, 2007).

A estruturação de currículos em CTS também é entendida numa perspectiva interdisciplinar. Isso significa que a discussão sobre as relações entre a ciência, a tecnologia e a sociedade não deve ser feita pela introdução de disciplinas como a Sociologia no currículo (AULER; BAZZO, 2001), mas deve encontrar espaço de articulação dentro das próprias disciplinas existentes.

No campo T\&E têm sido travadas intensas discussões em defesa da proposta de currículo integrado na educação profissional, pretendendo-se unir formação geral e formação profissional em um mesmo projeto. $\mathrm{O}$ pressuposto parte do ideal de "formação socialista que pretendia ser omnilateral no sentido de formar o ser humano na sua integralidade física, mental, cultural, política, científico-tecnológica" (CIAVATTA, 2005, p. 03). Essa autora acrescenta que os pilares do currículo integrado de EPT são trabalho, ciência e cultura, explicando que "a formação integrada sugere tornar íntegro, inteiro, o ser humano dividido pela divisão social do trabalho entre a ação de executar e a ação de pensar, dirigir ou planejar" (CIAVATTA, 2005, p. 02). Assim, a perspectiva curricular deverá englobar a amplitude do conceito de formação.

Tanto as propostas críticas do campo de T\&E para a EPT quanto os estudos sobre currículo com eixo CTS são contrários ao estreitamento da visão da formação. Ambas visam associar formação e exercício da cidadania. Em tais convergências é possível vislumbrar a possibilidade de combinação dessas duas perspectivas em eixos curriculares na EPT. Se os pressupostos do campo CTS demonstram estreita afinidade com os do campo T\&E, tal como se evidencia neste texto, parece razoável admitir-se a possibilidade de um currículo ser estruturado tendo os dois eixos - CTS e T\&E - articulados e entrelaçados. Esses apontamentos denotam ainda que a aproximação de ambos não os afasta de seus princípios ${ }^{4}$.

Não é difícil estabelecer relações de proximidade entre essas características de proposta curricular e as postuladas pelo campo T\&E. As possibilidades, porém, dependem da superação de duas lacunas nesses campos. Alguns autores se dedicam a discutir os pressupostos para a inserção da abordagem CTS no contexto educacional brasileiro (AULER; BAZZO, 2001); outros abordam o tema no interior de disciplinas em determinados níveis de ensino (SANTOS, MORTIMER, 2002), havendo ainda os que discutem o tema na perspectiva de sua inserção em níveis de ensino (PINHEIRO; SILVEIRA; BAZZO, 2007). Essas são discussões importantes, mas diante delas se evidencia a carência de bibliografias 
com abordagem ampla sobre currículo com eixo CTS, que permita a discussão em níveis menores ou a própria construção de propostas curriculares.

\section{CONSIDERAÇÕES FINAIS}

Tanto os pressupostos de CTS quanto os de T\&E, seja na concepção de educação politécnica, integrada ou omnilateral ou educação tecnológica, têm se pautado pela indissociabilidade entre conhecimentos teóricos e conhecimentos práticos. A formação científica pressuposta no campo CTS inclui uma visão ampla sobre a ciência, sobre seus fundamentos éticos e sociais, sobre suas finalidades e implicações. O campo T\&E tem evidenciado a necessidade de se formarem sujeitos que compreendam globalmente os fundamentos científicos do processo produtivo. A integração dos pressupostos definidos no campo T\&E para a EPT com os do campo CTS implica atualização e ampliação do conceito de formação. Isso lembra ainda que as relações entre homem, natureza, ciência e sociedade precisam ser repensadas.

Ciência e tecnologia ganham cada vez mais relevância, assim como o seu ensino, com implicações econômicas, sociais e ambientais, tornando-se questão crucial na educação. Nesse sentido, a integração entre o campo CTS e o de T\&E, especialmente no que tange aos pressupostos da EPT, amplia as possibilidades do currículo. Permite a discussão dos reais objetivos do ensino de ciência e tecnologia para além das determinações econômicas.

Aproxima-se, assim, de uma resposta que se quer mais cabal e que motivou a escrita deste artigo. Essa aproximação implica a introdução a um tema em que se evidenciam, além das possibilidades, lacunas. É clara a existência de pelo menos duas carências em produções teóricas: (i) produções que discutam currículo tendo como eixo estruturante CTS numa abordagem ampla - em outras palavras, que não concebam currículo reduzido a disciplinas, tampouco se limitem no ensino de ciências; e (ii) produções que associem as contribuições da abordagem CTS ao campo T\&E, de modo específico à EPT, superando lacunas nos estudos e pesquisas nesse campo e permitindo, ainda, a construção de propostas curriculares.

\section{NOTAS}

${ }^{1} \mathrm{O}$ conceito de "campo" foi tomado tal como definido por Bourdieu (1983, p. 122 -123): "sistema de relações objetivas entre posições adquiridas [...] [em que está em jogo] o monopólio da autoridade científica definida [...] como capacidade técnica e poder social [...] monopólio da competência científica [...] (grifos no original).

${ }^{2} \mathrm{~A}$ obra $A$ estrutura das revoluções científicas, de Thomas Kuhn, utilizada neste texto, é representada por sua quinta edição, publicada como parte da Coleção Debates - Editora Perspectiva, 1998. A obra Primavera silenciosa, de Rachel Carson, é representada por sua segunda edição - Editora Melhoramentos, 1969. 
Ciência, tecnologia e sociedade; trabalho e educação: possibilidades de integração no currículo da educação profissional tecnológica

${ }^{3}$ Disponível em <http://www.guardian.co.uk>. Acesso em: 05 maio 2011. ${ }^{4}$ Atribui-se a Thomas Kuhn o papel de um dos precursores do antirrealismo científico (HOSTINS, 2006). O antirrealismo científico afirma que o discurso faz parte da construção do objeto que supostamente descreve, opondo-se ao realismo científico, perspectiva segundo a qual a teoria representa a aproximação de um objeto que existe a priori. No entanto, é necessário ressaltar que, em $A$ estrutura das revoluções científicas, a perspectiva está inscrita no realismo.

\section{BIBLIOGRAFIA}

ARROYO, M. G. Revendo os vínculos entre trabalho e educação: elementos materiais da formação humana. In: SILVA, Tomaz Tadeu da (Org.). Trabalho, educação e prática social: por uma teoria da formação humana. Porto Alegre: Artes Médicas, 1991. p. 163-216.

AULER, D.; BAZZO, W. A. Reflexões para implementação do movimento CTS no contexto educacional brasileiro. Ciência \& Educação, v. 7, n. 1, p. 1-13, 2001. Disponível em: <http://www.cultura.ufpa.br/ensinofts/artigo4/ctsbrasil.pdf>. Acesso em: 25 abr. 2011. BOURDIEU, P. O Campo Científico. In: ORTIZ, Renato (org.). Coleção Grandes Cientistas Sociais, n. 39. São Paulo: Editora Ática, 1983.

BURNSIDE, J. Relutanct crusade. The Guardian, Londres - Inglaterra, 18 de maio de 2002. Climate Change. Disponível em: <http://www.guardian.co.uk/environment/2002/may/ 18/climatechange.physicalsciences?INTCMP=SRCH> . Acesso em: 03 maio 2011.

CARSON, R. Primavera silenciosa. 2. ed. (Tradução: Raul de Polillo). São Paulo: Melhoramentos, 1969.

CIAVATTA, M. Os Centros Federais de Educação Tecnológica e o ensino superior: duas lógicas em confronto. Educação e Sociedade [online], Campinas, vol. 27, n. 96 - Especial, p. 911-934, out. 2006. Disponível em: <http://www.scielo.br/pdf/es/v27n96/a13v2796. pdf>. Acesso em: 05 maio 2011.

A formação integrada: a escola e o trabalho como lugares de memória e de identidade. Trabalho necessário. ano 3, n. 3, 2005. Disponível em: < http://www.uff.br/trabalho necessario/TN03\%20CIAVATTA,\%20M..pdf>. Acesso em: 05 maio 2011.

FRIGOTTO, G. A relação da educação profissional e tecnológica com a universalização da educação básica. Educação e Sociedade [online], Campinas, vol. 28, n. 100, Número Especial, p. 1.129-1.152, out. 2007. Disponível em: <http://www.scielo.br/pdf/es/v28n100/ a2328100.pdf>. Acesso em: 03 maio 2011.

HOSTINS, Regina Célia Linhares. Formação de pesquisadores nos programas de pós-graduação em educação: embates ontológicos e epistemológicos. 2006. 176 f. Tese (Doutorado em Educação) - Universidade Federal de Santa Catarina, Santa Catarina, 2006. Disponível em: $<$ http://www.ppge.ufsc.br/ferramentas/ferramentas/tese_di/arquivos/53.pdf $>$. Acesso em: 28 ago. 2010.

GRINSPUN, M. P. S. Z. Educação Tecnológica. São Paulo: Cortez, 2003. 
KUHN, T. S. A estrutura das revoluções científicas. (Tradução: Beatriz Vianna Boeira e Nelson Boeira) 5. ed. São Paulo: Perspectiva, 1998. (Coleção Debates).

OLIVEIRA, M. R. N. Mudanças no mundo do trabalho: acertos e desacertos na proposta curricular para o Ensino Médio (Resolução CNE 03/98). Diferenças entre formação técnica e formação tecnológica. Educação e Sociedade. [online]. 2000, vol. 21, n. 70, p. 40-62. Disponível em <http://www.scielo.br/pdf/es/v21n70/a04v2170.pdf>. Acesso em: 13 abr. 2011.

PINHEIRO, N. A. M.; SILVEIRA, R. M. C. F.; BAZZO, W. A. Ciência, Tecnologia e Sociedade: a relevância do enfoque CTS para o contexto do Ensino Médio. Ciência e educação, Bauru, [online], vol.13, n.1, pp. 71-84, 2007. Disponível em: < http://www.scielo.br/pdf/ ciedu/v13n1/v13n1a05.pdf>. Acesso em: 18 abr. 2011.

SANTOS, W. L. P.; MORTIMER, E. F. Uma análise de pressupostos teóricos da abordagem C-T-S (Ciência-Tecnologia-Sociedade) no contexto da educação brasileira. Ensaio Pesquisa em Educação e Ciências, Belo Horizonte, vol.2, n.2, p. 1-23, Dez. 2002. Disponível em: <http://ufpa.br/ensinofts/artigos2/wildsoneduardo.pdf>. Acesso em: 25 abr. 2011.

Data de recebimento: 13/06/2011

Data de aprovação: 15/10/2011

Data da versão final: 01/12/2011 